\title{
Fiscal Stabilization and the Credibility of the U.S. Budget Sequestration Spending Austerity*
}

\author{
Ruiyang $\mathrm{Hu}$ \\ Southern Methodist University \\ Department of Economics, 3300 Dyer Street Suite 301, Dallas, TX 75275. \\ E-mail:rhu@smu.edu \\ Carlos E. Zarazaga** \\ Federal Reserve Bank of Dallas \\ Research Department, 2200 N.Pearl St., Dallas, TX 75206 \\ E-mail: carlos.zarazaga@dal.frb.org
}

\begin{abstract}
Fiscal imbalances predating the Great Recession but aggravated by it prompted the U.S. Congress to enact in 2011 legislation that, in the absence of other measures, would trigger two years later a so-called "budget sequestration" procedure that implied reducing government discretionary spending to unprecedented low levels over the following decade. For that reason, economic agents may not have expected this "fiscal stabilization measure of last resort" to be sustainable when it was put into effect in 2013 as scheduled. This is exactly the issue this paper set out to explore, on the grounds that sizing up the expectations that economic agents had about the budget sequestration can provide powerful insights on how fiscal stabilization is likely to proceed in the U.S. going forward. The paper makes inferences about the credibility enjoyed by the budget sequestration with an adapted version of the Business Cycle Accounting approach, originally developed for other purposes. The main finding is that the evidence favors a scenario in which spending cuts are half the size of those actually implied by the sequester. The paper takes this result as an indication that the U.S. is unlikely to address its unresolved fiscal imbalances with just austerity in discretionary spending, an interpretation consistent with existing literature that traces the seemingly anomalous behavior of economic variables during the Great Recession and its aftermath to alternative fiscal stabilization mechanisms.
\end{abstract}

* The views expressed herein do not necessarily reflect those of the Federal Reserve Bank of Dallas, or of the Federal Reserve System.

${ }^{* *}$ Corresponding author. 


\section{INTRODUCTION}

Five out of the seven advanced economies in the Group of Seven (G7) saw their government debts increased significantly in the wake of the Great Recession. In France, Italy, Japan, the United Kingdom, and the United States, the general government net debt, as reported by the International Monetary Fund, rose by about 30 to 50 percentage points of GDP between 2007 and 2015. As a result, in the latter year that debt concept represented at least $80 \%$ of GDP in those G7 nations, a figure large enough to prompt questions about their ability to keep meeting their obligations in the medium term without tolerating the erosion of their real value through higher inflation and/or taking deliberate actions to increase primary fiscal surpluses.

Particularly relevant for the purposes of this paper is the case of the U.S., whose general government net debt nearly doubled, from about 40 percent of GDP in 2007, to 80 percent of GDP just five years later, in 2012, when the recovery from the Great Recession was already in its third year. A similar surge of the U.S. government debt to historically high levels during World War II had not been a source of concern, as it was the result of the one-time steep rise in government expenditures generated by that war. But the one in peacetime just documented was more worrisome, because it couldn't be equally blamed on the circumstantially large deficits brought about by an infrequently deep economic contraction such as the Great Recession was. Even in the absence of that cyclical factor, under the fiscal policy configuration then in place the U.S. government debt would have been on an explosive trajectory, according to the December 2007 report on the long-term budget outlook by the Congressional Budget Office, a non-partisan federal agency responsible for periodically assessing the U.S. fiscal situation.

The perception that fiscal policy was on an unsustainable path prompted the U.S. Congress to include in legislation enacted on 2011- the Budget Control Act- several measures intended to rein in fiscal deficits. The one that motivates this paper was a contingent clause that, as explained by the Congressional Budget Office (2013), under certain circumstances would trigger a reduction of fiscal deficits over roughly the following decade for a cumulative amount of $\$ 1.2$ trillion (equivalent to about 10\% of GDP at the time) with the expedient procedure of automatically canceling, or sequestering (therein the origin of the term "budget sequestration" or "sequester"), beginning on January 2, 2013, "a portion of the budgetary resources for most discretionary programs as well as some programs and activities that generate mandatory spending."

As the qualifier "some" applied to entitlement programs in the quote above suggests, the often portrayed across-the-board automatic spending cuts would in practice fall mostly on government purchases of goods and services. Government consumption expenditures and gross investment would fall to such historically low levels as a result that it was reasonable to doubt that the budget sequestration could be sustained over time when the conditions triggering it did materialize by the dawn of 2013 .

The credibility of the rather draconian approach to fiscal stabilization just 
described is not therefore a foregone conclusion and needs to be investigated for the correct interpretation of the evidence for the period over which the U.S. economy was supposedly under the influence of that policy. In particular, studies seeking to attribute the dynamics of that country's macroeconomic variables over that reference period to different shocks and/or expectations of fiscal stabilization policies may reach the wrong conclusion if the analysis assumes that the spending cuts implied by the budget sequestration were credible, when they were not, and viceversa. A research agenda interested in this and related questions might find useful, therefore, the attempt of this paper to establish with some rigor the extent to which economic agents believed that government expenditures would be indeed reduced by as much as and for as along as implied by the budget sequestration procedure prescribed by the 2011 Budget Control Act.

A delicate methodological issue in that pursuit has been the choice of the analytical framework best suited to infer the credibility of that "fiscal stabilization measure of last resort" from the dynamics it induced in key macroeconomic variables, such as consumption, investment, and labor input. It seemed reasonable to expect that those inferences will inspire more confidence if obtained with a general equilibrium model flexible enough to accommodate different views about the features of the economic environment ultimately responsible for that dynamics.

That consideration led almost naturally to favor the business cycle accounting (BCA hereafter) approach proposed by Chari, Kehoe, and McGrattan (2007)CKM hereafter-which introduces in a widely used frictionless neoclassical growth model auxiliary variables ("wedges") that stand in for a variety of distortions (financial and/or nominal in nature) that the literature has postulated as essential for the correct interpretation of business cycle fluctuations and other phenomena. Besides this flexibility at capturing in a parsimonious way several frictions that have been considered in the literature, another advantage of the BCA approach for making statistical inferences is that it renders itself easily to a state-space representation of the wedges that replicates the data exactly. The paper exploits this feature of the BCA conceptual framework to calculate the likelihood of the data when the spending cuts were scheduled to come into effect, that is, in the year 2013, under different assumptions about their expected size and/or duration. To our knowledge, this is the first application of the BCA methodology to the study of a particular policy fiscal in this case event.

The reason to scrutinize particularly closely the available evidence for 2013 is that, given the time line of events briefly discussed above and in more detail later, it was that year when the credibility of the budget sequestration may have been at its peak and best captured, therefore, by the dynamics it induced on key macroeconomic variables at that time. The information contained in that same dynamics for subsequent years is less suitable for that purpose, because it was heavily contaminated by another large shock, the steep decline that oil prices experienced in 2014.

In the pursuit of establishing the extent to which the budget sequestration was a credible instrument of fiscal stabilization, the paper had to deal with 
three technical implementation issues. One was that, for the same reasons identified by Gomme and Rupert (2007), the accuracy of the inferences made with the statistical tools used in this paper could suffer from lack of correspondence between the variables in the model economy and their empirical counterparts. The paper minimizes this problem by adopting and updating the "private sector output" methodology to measure variables in the actual economy recommended by those two authors and by introducing in the model economy an external-like sector with the "minimalist" approach proposed by Trabandt and Uhlig (2011). Another issue was that the 2010 reform of the U.S. health care system (popularly referred to as "Obamacare") introduced, effective as of 2013, a surtax of $3.8 \%$ on net investment income that amounted in practice to increasing by as much the capital income tax rate. It was necessary to take into account, therefore, that the dynamics of the macroeconomic variables of interest in that year was under the influence not only of the mostly unanticipated automatic reductions of government expenditures, but also of the higher capital income tax rate anticipated as of three years before. The third complication was the lack of consensus in the profession about the values of two key macroelasticities, the labor-held-constant intertemporal elasticity of substitution in consumption (IES hereafter) and, in particular, the marginal-utility-of-wealth-held-constant elasticity of labor supply ("Frisch elasticity"). As is well known, these parameters control the relative strength of the wealth and substitution effects activated by a variety of shocks, including the policy regime change that motivates this paper, and therefore the overall dynamics of macroeconomic variables in response to them. The credibility of the budget sequestration had to be investigated, therefore, for several combinations of specific values of those parameters commonly used in the literature.

The paper finds that, for all the macroelasticity values considered, the budget sequestration was only partially credible. Specifically, the likelihood of the data favors an intermediate scenario in which households and businesses were making their decisions in 2013 as if the annual reductions in government purchases of goods and services were going to be only half the size of those implied by that fiscal stabilization procedure of last resort. It doesn't seem implausible to maintain that these expectations, far from totally subjective, revealed the presence of hidden objective factors otherwise difficult to detect. For example, economic agents could have been skeptical that the budget sequestration could be sustained if they correctly perceived lack of popular support for the severe spending austerity it implied.

In any case, the finding that the budget sequestration spending cuts were less than fully credible seems to be validated by recent studies inspired by the apparently anomalous behavior that the same economic variables examined in this paper exhibited during the Great Recession and its aftermath. For example, Lucas (2011) has offered the conjecture, formally explored in Kydland and Zarazaga (2016), that the prospect of higher taxes could account for the weak recovery from the Great Recession. In the same spirit of explaining away anomalies in the predictions of existing models, Fratto and Uhlig (2014) have speculated that the "missing deflation" during and after that contraction in 
models built in the Neokeynesian tradition could be the result of fiscal stabilization being de facto achieved by the mechanism emphasized by the so-called fiscal theory of the price level, that is, by the price level rising by enough to bring the real value of the nominal government debt in line with the present value of whatever future primary fiscal surpluses the government is expected to deliver. The finding of this paper is certainly consistent with these two not necessarily mutually exclusive hypotheses and suggests that new insights could be gained by revisiting them with the methodological approach proposed in this paper.

\section{BACKGROUND MATERIAL}

\subsection{THE BUDGET SEQUESTRATION: RELEVANT CHRONOLOGY AND DETAILS}

In the U.S., the government can borrow to finance any shortfall of revenues relative to expenditures as long it doesn't go over a certain "debt ceiling" explicitly authorized by Congress. The authorization step is usually a formality, as it simply provides the U.S. Treasury the means to pay for government spending previously agreed upon. That was not the case, however, in January 2011, when the U.S. Treasury request for a debt ceiling increase met considerably resistance from a large number of lawmakers concerned with the explosive debt scenario projected by a recent June 2010 report from the Congressional Budget Office, considered realistic by many budget analysts according to the document. These legislators demanded, therefore, that any increase in the debt ceiling was accompanied with fiscal deficits reduction measures that prevented that scenario from happening. There was, however, considerable disagreement on what those specific measures should be and the prolonged negotiations to resolve the differences put the U.S. at the brink of a sovereign debt default. A last minute agreement avoided that outcome with the Budget Control Act signed into law on August 2, 2011. The result of a difficult compromise, the law was unavoidably complex, as it had to put to rest the fears of an explosive government debt scenario by significantly reducing fiscal deficits in two installments.

The first installment was delivered by imposing caps effective immediately on discretionary funding through 2021, which according to a detailed CBO analysis of the legislation would bring government discretionary spending as a share of GDP down from the relatively high levels observed after the Great Recession to the relatively low levels observed in the decade prior to that contraction. The second installment would reduce fiscal deficits by an additional amount of $\$ 1.5$ trillion (equivalent to about $10 \%$ of GDP at the time) over the period of fiscal years 2012-2021 with the specific measures recommended by a bipartisan Joint Select Committee on Deficit Reduction the law created to that effect.

In order to provide the incentives to accomplish that goal to lawmakers presumably loath to indiscriminate spending cuts potentially harmful to their constituents, the Budget Control Act included a provision stating that if the Joint Committee failed to propose or Congress failed subsequently to enact legislation to cut the deficit by at least $\$ 1.2$ trillion by January 15,2012 , the caps 
on discretionary budget authority imposed by the first installment of fiscal stabilization measures would be reduced further in the cumulative amount just mentioned, starting in January 2, 2013 and throughout fiscal year 2021. In practice, this contingent clause meant that the fiscal deficit reduction second installment would accomplish its alleged fiscal stabilization goal either with the deliberate measures suggested by the Joint Select Committee or, in their absence, with automatic spending cuts evenly split between discretionary defense and non-defense programs, over and above those specified in the first installment.

Technically speaking, the law under discussion prescribed the application of the "budget sequestration" administrative procedure to expenditures that exceeded the caps, but legally not subject to them because they had been authorized by previous legislation. This procedure therefore revoked ("sequestered") de facto that authorization, in the amount needed to conform to the new caps. It is for this reason that this second installment of automatic spending cuts is generically referred to in this paper as budget sequestration cuts, even if strictly speaking sequestration applied only to the specific budget items just mentioned.

An important detail for building a model economy that adequately captures critical features of the actual one under study is that it was understood that the budget sequestration would not fall on the sizable federal government outlays originated by civil and military payrolls. This measure wasn't projected, therefore, to have a visible effect on public sector employment, a feature that made it possible to circumvent the measurement difficulties hinted at in the introduction by considering a model economy in which the government doesn't make any contributions to value added and the spending cuts under study simply take the form of a lower government absorption of goods and services exclusively produced by the private sector.

In any case, it follows from the preceding discussion that the spending cuts implied by the first installment of deficit reduction measures contained in the Budget Control Act were not out of the ordinary in size by historical standards. As such, an outside observer unaware of any changes in legislation would not see anything unusual in their implied levels of government spending on discretionary programs as a share of GDP, just one more of many dips that this ratio has exhibited over the years while fluctuating around its long-run mean. In the empirical implementation of the model, therefore, it will be assumed that, absent a permanent policy regime change, the government absorption of goods and services as a share of GDP evolves over time as if governed by a stationary stochastic process.

Such an interpretation is more difficult to maintain for the second installment of spending cuts implied by the budget sequestration, because if actually implemented, the ratio just mentioned would be at its lowest levels on record at the expiration of the budget sequestration, according to Congressional Budget Office (2012) estimates. ${ }^{1}$ It seems more appropriate, therefore, to treat

\footnotetext{
${ }^{1}$ More specifically, in table 1-1 of the cited CBO report, discretionary spending at the end
} 
the budget sequestration as a temporary policy regime change, deliberately designed to deliver such harsh fiscal spending austerity that legislators would be compelled to agree on accomplishing the same fiscal deficit reduction target by other means.

The strong incentive to cut a deal instead of spending supposedly introduced by the rather blunt budget sequestration threat didn't seem to be working as intended, however, when on November 21, 2011 the Joint Committee announced that, "after months of hard work and intense deliberations," it had come to the conclusion that it wouldn't be possible to reach an agreement on an alternative fiscal deficit reduction package before the January 15, 2012 deadline specified in that law.

Still, the fact that the cuts would reduce discretionary spending as a share of GDP to levels not seen before, eventually impairing the ability of government agencies to adequately perform core functions, kept alive throughout all of 2012 the hopes that Congress in the end would act to avoid them. Such hopes weren't misplaced, given that lawmakers were considering whether or not to extend tax cuts enacted in 2001 and 2003 due to expire precisely that year. It was plausible to speculate that the negotiations inevitably required to change the tax code would offer legislators a golden opportunity to come up with alternative deficit reduction measures that met the conditions to cancel, or at least suspend, the dreadful budget sequestration. Such speculation may have been reinforced by repeated public statements from Congress and even the President of the United States insisting on their determination to find a compromise. In fact, according to press reports, the Department of Defense, one of the federal agencies that would be hit particularly hard by the spending cuts, wasn't making any contingent plans to deal with them as late as September 2012.

It is fair to conjecture then that at the end of 2012 the credibility of a budget sequestration, so widely regarded as unreasonable in depth and scope, was very low. But that may have changed drastically, and this is precisely what the paper sets out to investigate, when the Taxpayer Relief Act passed by the U.S. Congress on the dawn of 2013 did make the modifications to the tax code prompted by the expiration of previous tax provisions, but failed to take any substantial action with respect to the budget sequestration, other than postponing its implementation by two months, from its originally slated date, January 2, 2013, to March 1, 2013.

The passage of that law may have convinced households and businesses that the budget sequestration was no longer a distant, unlikely event. If that was indeed the case, the resulting shift of expectations should have triggered a rather quick adjustment of their behavior, eventually captured particularly well by their decisions to consume, invest, and work during 2013. The paper takes the stand, therefore, that the evidence for that year is endowed with "quasiexperimental" attributes almost ideal for making inferences about the extent to

of the sequestration period, in 2021, is projected to represent 5.7 of GDP, the lowest level observed since at least 1972 . 
which the spending austerity implied by the budget sequestration was a credible fiscal stabilization policy.

Those inferences will depend crucially on the exact magnitude and distribution of the budget sequestration cuts in real terms over time. Establishing that is not as straightforward as it may seem, because given the standard legislatures' practice of approving government budgets, spending limits such as the ones discussed above determine the sequence of spending cuts only in nominal terms. Transforming that sequence to one in real terms requires, therefore, to make assumptions about the expected inflation rate over the budget sequestration period. In addition, it is necessary to make assumptions about the growth rate of real output over this same period when, as in this paper, the budget sequestration is interpreted as a policy regime change that shifts downwards for its duration the stochastic process otherwise governing the evolution of the government spending-output ratio over time.

In any case, the calculation of the spending cuts implied by the budget sequestration in real terms must necessarily start out from a reliable sequence of nominal ones. Fortunately, such a sequence can be readily constructed from the data provided in an analysis of the budget sequestration by the Congressional Budget Office (2013), as summarized in the second column of Table 1. The nominal values were converted to real ones by assuming an annual expected inflation rate equal to the Federal Reserve target for that variable, $2 \%$, and an annual growth rate of real output of $2 \%$ also, consistent with the long-run growth rate of this variable suggested by the calibration of the model discussed later. More specifically, these rates were used to construct series for the price index for non-durable goods and services and for real GDP for the intended duration of the sequester, the period 2013-2021, taking as reference the observed values of those indices in 2012.

The third column in Table 1 documents the spending cuts in real terms implied by the budget sequestration adopted by the paper, calculated by dividing the corresponding nominal sequence by the indices just described and grossing up the result by 15 percent. The last step was dictated by internal consistency with the empirical methodology, which when appropriate represents variables as shares of output produced by private sector businesses, about that percentage lower than total output when the value added by government agencies and enterprises is excluded from it.

The Budget Control Act didn't stipulate spending caps past the year 2021, so it didn't impose any legal restrictions on the level of government absorption of goods and services as a share of GDP in the long run. The value of this ratio in the long run is needed, however, because the steady state equilibrium of the model economy will be an important reference for the empirical implementation of the BCA approach adopted by the paper. The developments summarized above suggest that the budget sequestration was a fiscal stabilization measure of last resort and, as such, not intended to persist beyond the period explicitly established in the legislation. Accordingly, the paper assumes that at the end of the budget sequestration period, the government absorption of goods and services as a share of GDP returns to its historical average, as measured in 
Table 1: Annual budget sequestration spending cuts

\begin{tabular}{|c|c|c|}
\hline Year & \$ billion $\left(^{*}\right)$ & \% of model economy output \\
\hline 2013 & 35 & 0.24 \\
\hline 2014 & 75 & 0.49 \\
\hline 2015 & 85 & 0.53 \\
\hline 2016 & 89 & 0.54 \\
\hline 2017 & 90 & 0.52 \\
\hline 2018 & 90 & 0.50 \\
\hline 2019 & 89 & 0.48 \\
\hline 2020 & 88 & 0.45 \\
\hline 2021 & 87 & 0.43 \\
\hline$\left.{ }^{*}\right)$ Congressional Budget Office $(2013)$, p. 10 and Table 1-5, p. 27 \\
\hline \multicolumn{2}{|c}{} \\
\hline
\end{tabular}

section 3.4 of the paper.

Finally, another detail with implications for the evidence that will be examined in the paper is that, as mentioned in the introduction, the Health Care and Education Reconciliation Act of 2010 introduced an additional tax of $3.8 \%$ on net investment income- a form of capital income taxation- that would enter into effect in 2013, precisely at the same time that the circumstances described above triggered the budget sequestration under study.

\subsection{MEASUREMENT ISSUES}

As mentioned in the introduction, the paper will examine with a BCA approach the dynamics of key macroeconomic variables at the time the budget sequestration was launched, to make inferences about the credibility of the spending cuts implied by this procedure and, therefore, about the extent to which it was believed that this fiscal stabilization measure of last resort would achieve the intended fiscal stabilization goal. It seemed important for this project, therefore, to be particularly worried about the imprecision eventually introduced in those inferences by an implementation of the BCA methodology that ignored, as is common in the literature, the measurement issues discussed by Gomme and Rupert (2007).

As pointed out by those authors, the textbook neoclassical growth model implicitly assumes that all economic decisions are made by utility-maximizing households and profit-maximizing firms. But in actual economies, measured output includes goods and services that the government provides as a result of administrative and/or political decisions, hardly dictated by the same incentives as those faced by the private sector. The absence of prices for such publicly provided goods and services is a manifestation of that reality, and the reason why the non-market output produced by the government is typically measured in most national accounts, including in the U.S. National Income and Product Accounts (NIPA), by the costs of producing publicly provided goods and services, 
that is, by the inputs used up or "consumed" in the process of generating that output.

In the U.S., the government non-market component of output, identified in NIPA as "government consumption expenditures and gross investment," represents about $19 \%$ of total output. This is certainly a fraction of output large enough to give rise to imprecise inferences about the actual economy if the model intended to represent it is built on the assumption that the quantities of all types of goods and services produced in the former reflect the interaction of optimizing private agents that value them at market prices.

Similar measurement issues distort the NIPA estimates of income. In particular, NIPA treats the income flows generated by the services from the capital stock differently, depending on whether that stock is owned by the public or the private sector. This asymmetry introduces a distortion in the measurement of aggregate output that may be subsequently transmitted to other key parameters and variables, such as the share of the remuneration to the capital input in total income, or the series for total factor productivity (TFP) calculated from Solow residuals.

Gomme and Rupert argued in the paper already mentioned that these potentially severe measurement problems can be considerably mitigated by improving the mapping between the neoclassical growth model and the data with a model in which all output is the result of value added exclusively by the private sector. The empirical counterpart of this concept is obtained by subtracting from real GDP the value added by the general government in the process of producing non-market goods and services. This "private sector economy" approach is not an obstacle to make inferences about the credibility of the budget sequestration cuts because, as mentioned earlier, they fell mostly on the government absorption of goods and services produced by the private sector, rather than on the value added by the government, a large fraction of which is just the compensation of the labor services provided by government employees.

The data necessary to obtain the historical series of private sector output in a manner consistent with the way government economic activities are recorded in NIPA are available at an annual frequency only since 1977. The analysis in this paper uses therefore data from that year until 2013, the year that the budget sequestration began. A thorough discussion of the steps required to make the data for the 1977-2013 period consistent with the conceptual entities in the model are rather involved and would detract from the main focus of the paper. Interested readers in the details will be able to find them, however, in Kydland and Zarazaga (2016), who applied an entirely analogous procedure in the process of answering a different question.

\section{THE MODEL ECONOMY}

Given that the paper has adopted a BCA approach to make inferences about the credibility of the budget sequestration, it seemed sensible to respect the principle generally followed by previous implementation of that approach that 
the long-run features of aggregate models should be consistent with the balanced growth facts documented by Kaldor (1961). Accordingly, preferences, technology, and government policies have been restricted to the types that are consistent with balanced growth, as characterized by King, Plosser, and Rebelo (1988a, b). Moreover, in line with the usual tradition in applications of this approach, whenever possible the relevant parameter values were calibrated to long-run features of the U.S. economy, in the manner discussed in detail later.

All real variables were obtained by dividing their nominal counterparts by the price index of non-durable goods and services. This procedure guarantees that all investment-specific technological progress is transformed in labor-augmenting technological progress, the only kind of technological progress consistent with balanced growth, as discussed in King, Plosser, and Rebelo.

Also, when applicable, all real variables are represented in terms of per population 16 years of age and over and detrended by the long-run growth rate of total factor productivity. This procedure typically removes the secular trend from the variables of interest. The exception is the fraction of available time that households are at work in the private sector, which exhibited a clearly rising trend in the U.S. until recently, and had to be rendered stationary with the procedure explained in subsection 3.4.

\subsection{THE TYPICAL HOUSEHOLD'S CHOICE PROBLEM}

The model economy is assumed to be inhabited by an infinitely-lived household, which stands for the large number of them present in the actual economy and whose preferences can be ordered by a time-separable Constant Frisch Elasticity (CFE hereafter) utility function defined over infinite streams of consumption $\left\{c_{t}\right\}_{t}^{\infty}$ and the fraction of available time devoted to work $\left\{h_{t}\right\}_{t}^{\infty}$. In addition to being consistent with balanced growth, this utility function is the only one that allows consumption and leisure to be non-separable within periods without at the same time tying the value of the Frisch elasticity to that of the IES and to the fraction of time devoted to work. Given the purpose of this paper, the flexibility of this utility function for specifying different values for the Frisch elasticity and the IES was important for conceptual and computational reasons.

The conceptual reason is that the strength of the response of endogenous macroeconomic variables to a fiscal policy change as the one studied in this paper is controlled not only by the credibility inspired by the policy, but also by the value of the two macroelasticities just mentioned. Given the considerable disagreement about those values prevailing in the profession, it seemed prudent to explore the credibility of the budget sequestration with a utility function consistent with combinations of them that would be disallowed by the one-toone correspondence between the value of the IES and that of the Frisch elasticity implied by the alternative popular Constant Elasticity of Substitution (CES) specification for the utility function also consistent with balanced growth.

An equally important consideration for the adoption of CFE utility function specification is that the equilibrium allocations of the model economy will be 
computed with perturbation methods that approximate the private sector's decision rules in the neighborhood of the non-stochastic steady state of the model economy. The unavoidable approximation errors introduced by this computational technique are likely to be compounded by utility function specifications that imply that the Frisch elasticity varies with the fraction of available time devoted to market activities, as is the case with the CES specification just mentioned.

Accordingly, the stand-in household is assumed to solve the following maximization problem:

$$
\underset{\left\{c_{t}, h_{t}, k_{t+1}\right\}}{\operatorname{Max}} E \sum_{t=s}^{\infty}\left[\beta(1+\gamma)^{1-\sigma}(1+\eta)\right]^{t} \frac{c_{t}^{1-\sigma}\left[1-\kappa(1-\sigma) h_{t}^{1+\frac{1}{\varphi}}\right]^{\sigma}-1}{1-\sigma}
$$

subject to the following constraints:

$$
\begin{aligned}
c_{t}+\left(1+\tau_{t}^{x}\right) x_{t}= & \left(1-\tau_{t}^{h}\right) w_{t} h_{t}+r_{t} k_{t}-\tau^{k}\left(r_{t}-\delta\right) k_{t}+n i_{t}+\tau_{t} \\
x_{t}= & (1+\eta)(1+\gamma) k_{t+1}-(1-\delta) k_{t} \\
1= & l_{t}+h_{t} \\
h_{t}= & h_{t}^{p r}+h_{t}^{p u} \\
& \quad \text { government policies }
\end{aligned}
$$

The relevant details and notation of this stand-in household maximization problem are discussed next.

The objective function in (1) is the expected discounted value of a utility function in the CFE class, where $\beta>0$ is the discount factor, $\eta$ is the working age population annual growth rate, $\gamma$ the annual growth rate of total factor productivity, $t$ a time index, $c_{t}$ detrended consumption per working age person, $h_{t}$ the fraction of available time the representative household allocates to work in the market, $\sigma>0$ is the inverse of the IES (labor-held-constant intertemporal elasticity of substitution in consumption), $\kappa>0$ a parameter that controls the household's valuation of consumption relative to leisure, and $\varphi$ the constant Frisch elasticity of aggregate labor supply.

Notice that the discount factor $\beta$ appears multiplied by the factor $(1+$ $\eta)(1+\gamma)^{(1-\sigma)}$. This is one adjustment required to make stationary economic variables that otherwise would display secular growth. This transformation is valid because, as mentioned at the beginning of this section, the model economy will meet the conditions required for balanced growth. The already mentioned work of King, Plosser, and Rebelo, as well as others cited therein, has shown that such an economy can be transformed into an economy without growth, provided the relevant variables are detrended by their underlying secular growth rates and the appropriate parameters, such as the discount factor, are adjusted as dictated by theory.

The economy without growth displays the same transitional dynamics as the original one, but is more convenient to work with when, as in the case of this paper, the technique for computing the equilibrium allocations involves 
Taylor expansions of the first-order conditions around the deterministic steadystate. For that reason, the discussion that follows will refer exclusively to the model economy without growth, in which all the adjustments with respect to the original economy with growth have been performed already. In particular, the discount factor in (1) has been adjusted as indicated above and the consumption good that appears as an argument in the utility function has been detrended by the average growth rate of U.S. output.

Equation (2) is the household's budget constraint, where $x_{t}$ is gross private domestic investment, $w_{t}$ the wage rate in terms of consumption per unit of the available time the stand-in household devotes to work, $r_{t}$ the rental price of period $t$ private sector capital, $k_{t}, \tau^{k}$ the tax rate on income from that capital, $\delta$ the depreciation rate, and $\tau_{t}$ lump-sum transfers (taxes if negative.) The three symbols not discussed yet, $\tau_{t}^{x}, \tau_{t}^{h}$ and $n i_{t}$, introduce in the model three of the four "wedges" that will implement the BCA approach that the paper exploits to make inferences about the credibility of the budget sequestration. In particular, $\tau_{t}^{x}$ and $\tau_{t}^{h}$ play the same role as in Chari, Kehoe and McGrattan (2007), by determining what those authors refer to, respectively, as the labor wedge, $1-\tau_{t}^{h}$, and the investment wedge, $1 /\left(1+\tau_{t}^{x}\right)$.

The variable $n i_{t}$ stands for net imports and captures the net exports component of aggregate demand that CKM lumped together with a government consumption wedge. Consolidating these two wedges into one didn't seem appropriate for the purposes of this paper, because inferring the credibility of the spending cuts from the dynamics of macroeconomic variables around the time the budget sequestration was triggered requires to distinguish the effects on that dynamics induced by those cuts from the effects induced by the stochastic external sector wedge, $n i_{t}$. Furthermore, the introduction of this wedge in the minimalist manner proposed by Trabandt and Uhlig (2011) mitigates the lack of correspondence between the otherwise closed economy model of this paper and the data for the U.S. economy, whose economic interactions with the rest of the world would have been considerably more challenging to model and parameterize explicitly. Introducing this admittedly crude adjustment seemed nevertheless important, because a negative trade balance is the counterpart of the flow of income from foreign assets that households can devote to investment, a variable that will be important for making inferences about the extent to which households and firms expected that the spending cuts would be implemented over time as prescribed by the budget sequestration.

The empirical implementation of the model will take into account that in balanced growth the ratio of this variable to output should be characterized by a stationary stochastic process with unconditional mean niy. Subsection 4.2 will provide further details about this process, as well as of those governing the evolution over time of the labor wedge $\tau_{t}^{h}$ and of the investment wedge $\tau_{t}^{x}$.

Equation (3) states the evolution over time of the capital stock that the household rents to private firms which, for consistency with the NIPA methodology, excludes the public sector capital stock. This law of motion links the private capital stock available for production at the beginning of a period, $k_{t}$, with the households' investment decisions during that same period, $x_{t}$, and with 
the private capital stock that will be available at the beginning of the following period, $k_{t+1}$.

In line with the treatment of macroeconomic aggregates introduced before, those in the law of motion (3) have also been detrended and are measured in units of the consumption good per working age person. In fact, the correction of the beginning-of-period $t+1$ capital stock by the gross growth rate factor $(1+\eta)(1+\gamma)$ is the other adjustment that is necessary to transform the original balanced growth economy into one without growth, but with the same quantitative properties in terms of impulse-responses and transitional dynamics.

Equation (4) states the time constraint that the stand-in household can distribute its total available time, normalized to 1, among non-market activities, $l_{t}$, (generically labeled as "leisure") and work in the marketplace, $h_{t}$.

Equation (5) states that the household can allocate the time it devotes to work between private sector firms, $h_{t}^{p r}$, and public sector agencies (inclusive of government-owned enterprises), $h_{t}^{p u}$. Note that for consistency with the standard treatment of labor input in the neoclassical growth model, the empirical counterpart of variable $h_{t}$ is the fraction of time actually worked, not just paid. The data were therefore adjusted to exclude the time for which workers were paid but not actually working, because they were on vacation, sick leave, etc.

The explicit distinction between the time households devote to work in the public and private sectors is uncommon, because the value added by both, the private and public sectors, is deemed the appropriate empirical counterpart of output in most models. This is not true for the model economy of this paper, in which all the value added is provided by the private sector, even if partly absorbed by government purchases not valued by the stand-in household. Calibrating or estimating the relevant parameters of such an economy without taking into account the fraction of time that households work for government agencies could lead to overestimate the labor input absorbed by the private sector and, therefore, output, consumption, and investment in the private-sector-only economy.

\subsection{PRIVATE SECTOR FIRMS' MAXIMIZATION PROBLEM}

There are two kinds of firms that produce output in the stationary economy without growth and without a government final good: private firms and government enterprises. As pointed out by Gomme and Rupert in the paper repeatedly mentioned, the decisions of the latter are guided by administrative, rather than profit-maximizing considerations and are taken, therefore, as exogenous.

The behavior of private firms is instead modeled explicitly, an approach that requires one to be specific about the restrictions those firms face in the production of output. The paper adopts the standard assumption that the model economy is populated by a large number of identical private firms that transform labor and capital inputs into output with a constant returns to scale technology that exhibits labor-augmenting technical progress and unitary elasticity of substitution between inputs. Under those conditions, the aggregate output of the model economy corresponds to that generated by a single representative firm 
endowed with a Cobb-Douglas production function:

$$
y_{t}^{p r}=\frac{1}{e^{(1-\theta) \gamma t}} A e^{(1-\theta) z_{t}} k_{t}^{\theta}\left[e^{\gamma t} h_{t}^{p r}\right]^{1-\theta},
$$

where $y_{t}^{p r}$ is the output per working age person produced by private sector firms, $\theta$ the proportion of the remuneration to capital services in the private sector value added, and $z_{t}$ is a stochastic technology level that introduces the fourth wedge considered for the particular implementation of the BCA methodology carried out in this paper. This technology level shifter corresponds conceptually to the efficiency wedge in CKM. The properties of the stochastic process governing its evolution over time will be discussed in subsection 4.2 .

Given that all variables have been detrended, the growth factor $e^{\gamma}$ in (7), approximated by $(1+\gamma)$ in the quantitative implementation of the model, is obviously redundant and will be eliminated later. It was made explicit here, however, in order to emphasize that the model economy is characterized by secular technical progress that the Cobb-Douglas production function permits one to represent as labor augmenting. As shown by Greenwood, Hercowitz, and Krusell (1997), when the production function is of that type, an economy that exhibits investment-specific, or capital-embodied, technological change can be represented as one with labor-augmenting technical progress, provided the depreciation rate in (3) is interpreted as the economic, rather than physical, depreciation rate. ${ }^{2}$

The representative firm that stands for the large number of them making decisions in the economy solves, therefore, the following maximization problem:

$$
\underset{h_{t}^{p r}, k_{t}}{\operatorname{Max}}\left[A e^{(1-\theta) z_{t}} k_{t}^{\theta}\left(h_{t}^{p r}\right)^{1-\theta}-w_{t} h_{t}^{p r}-r_{t} k_{t}\right] .
$$

Notice that in this economy, it is the stand-in household that makes the investment decisions. Absent the intertemporal dimension, the representative firm's problem reduces to a sequence of static, single-period problems.

\subsection{PUBLIC SECTOR POLICIES}

As mentioned in subsection 2.2, the allocation of resources by public sector entities is the result of complex social, political, and economic considerations, not aptly captured by the same profit- and utility-maximizing incentives faced by households and private sector firms. Given the difficulties in modeling explicitly the behavior underlying the economic decisions made by public sector agencies, the variables under their control will be exogenously determined.

\subsubsection{GOVERNMENT BUDGET CONSTRAINT AND THE SEQUESTER}

As hinted at in subsection 2.1, the paper views the budget sequestration as a last resort measure to address looming U.S. fiscal imbalances. The fiscal

\footnotetext{
${ }^{2}$ The constant economic depreciation rate in (3) assumes implicitly as well a constant growth rate of investment-specific technological progress.
} 
solvency that this measure intended to ensure can be captured with a government budget constraint that makes abstraction of government debt and that, therefore, implicitly imposes the restriction that any change in the government purchases of goods and services (excluding labor services counted in government value added) will be offset by a corresponding change in revenues. Thus, in the model the government absorption of output exclusively produced by the private sector, denoted $g a_{t}$, will be assumed to be equal every period to revenues from all sources minus transfer payments, as indicated by the following government budget constraint:

$$
g a_{t}=\tau_{t}^{h} w_{t}\left(h_{t}^{p r}+h_{t}^{p u}\right)-w_{t} h_{t}^{g c}+\tau^{k}\left(r_{t}-\delta\right) k_{t}+s_{t}^{g e}-\tau_{t},
$$

where $h_{t}^{p u}$ is equal to $h_{t}^{g c}+h_{t}^{g e}$, with $h_{t}^{g c}$ and $h_{t}^{g e}$ representing the fraction of time the stand-in household works for government agencies and governmentowned enterprises, respectively, where $s_{t}^{g e}$ denotes, for consistency with the NIPA methodology, surpluses (deficits, if negative) transferred by government-owned enterprises, and where $\tau_{t}$ stands for lump-sum transfers. In line with the treatment of variables corresponding to physical quantities discussed before, those of the same type in the government budget constraint are measured in units of the consumption good per working age population as well.

To avoid misunderstandings, it is worth to emphasize at this point that the variable $g a_{t}$ is conceptually different from the government consumption expenditure variable in CKM, which in the case of those authors does include value added by the government sector and, in addition, net exports. Moreover, for the purpose of the present paper it will be convenient to interpret this variable as made up of a systematic, exogenous stochastic component, ega $a_{t}$, and of a nonsystematic, deterministic component, $p g a_{t}$, whose relationship, after division by private sector output, can be formally represented as follows:

$$
\frac{g a_{t}}{y_{t}^{p r}}=\frac{e g a_{t}}{y_{t}^{p r}}+\frac{p g a_{t}}{y_{t}^{p r}} .
$$

In line with the historical developments described in section 2.1 , the stochastic component ega $a_{t}$ is meant to capture the ups and downs of the government spending policy historically followed until the sequestration took place in 2013. The non-systematic, deterministic component $\mathrm{pga}_{t}$ is meant to capture the "policy regime change" of limited duration (from 2013 to 2021, to be precise) implied by the budget sequestration spending cuts.

For consistency with the balanced growth assumption, the stochastic component is postulated to evolve over time according to a stationary stochastic process with the following autoregressive representation:

$$
\ln \frac{e g a_{t}}{y_{t}^{p r}}=\left(1-\rho_{g a}\right) \ln g y+\rho^{g a} \ln \frac{e g a_{t-1}}{y_{t-1}^{p r}}+\sigma_{g y} \varepsilon_{t}^{g y},
$$

where $g y$ and $\sigma_{g y}$ are scalars, and $\varepsilon_{t}^{g y}$ is a random variable with a standard normal distribution. 
The policy component in (10), $\frac{p g a_{t}}{y_{t}^{p t}}$, is a placeholder that will be replaced by the spending cuts in the third column of Table 1 in the quantitative implementation of the model, with the practical effect of shifting down the government absorption of private output relative to the level implied by the exogenous component $\frac{e g a_{t}}{y_{t}^{p t}}$.

\subsubsection{PUBLIC SECTOR LABOR DEMAND}

The general government and government enterprises' demand for labor services is assumed to be constant, except for the additive transient fluctuations captured by the following simple stochastic processes:

$$
\ln h_{t}^{p u}=\ln h^{p u}+\sigma_{h p u} \varepsilon_{t}^{h p u}
$$

where $h^{p u}$ and $\sigma_{h p u}$ are scalars and $\varepsilon_{t}^{h p u}$ is a random variable characterized by a standard normal distribution.

\subsubsection{GOVERNMENT ENTERPRISES VALUE ADDED}

The value added by government enterprises, $v a_{t}^{g e}$, included in the business rather than the government sector of NIPA, should grow at the same rate as private sector output along a balanced growth path. Therefore, it is natural to postulate that the evolution of this variable over time is determined by the following stochastic processes:

$$
\ln \frac{v a_{t}^{g e}}{y_{t}^{p r}}=\ln v y+\sigma_{g e} \varepsilon_{t}^{g e}
$$

where $v y$ and $\sigma_{g e}$ are scalars, and $\varepsilon_{t}^{g e}$ is a random variable characterized by a standard normal distribution.

\subsubsection{RESOURCE CONSTRAINT}

For the purpose of subsequent analysis, it is useful to make explicit the resource constraint that results from consolidating the household's budget constraint (2) with the government budget constraint (9), after taking into account that, for consistency with the NIPA methodology, output in the model economy originates in private sector firms according to (7) and in government-owned enterprises according to (13):

$$
c_{t}+\left(1+\tau_{t}^{x}\right) x_{t}=\left[1+\frac{v a_{t}^{g e}}{y_{t}^{p r}}-\frac{g a_{t}}{y_{t}^{p r}}+\frac{n i y_{t}}{y_{t}^{p r}}\right] A e^{(1-\theta) z_{t}} k_{t}^{\theta}\left(h_{t}^{p r}\right)^{1-\theta} .
$$

\subsection{MODEL CALIBRATION}

As suggested by the previous exposition, the comparison of the model predictions with the data will play an important role in establishing the credibility of the budget sequestration spending cuts with the adapted BCA methodology implemented in this paper. For that reason, it was critical to ensure the correspondence between the detrended variables assumed for the model and their 
empirical counterparts. As indicated above, this was accomplished by dividing period $t$ observed real variables subject to secular growth by the annual balanced growth factor $[(1+\gamma)(1+\eta)]^{t}$. This standard procedure wasn't sufficient, however, to render all variables stationary in the case of the U.S., because in that country the fraction of time that households devoted to work, $h_{t}$, rose steadily over the three decades that preceded the Great Recession, with a pattern inconsistent with the stationarity of that variable along a balanced growth path predicted by the neoclassical growth model. Ignoring this dynamics of labor input could severely distort the correspondence between the model and the data, with unpredictable consequences for the empirical results of this paper. Therefore, detrending the data for this project required to remove the transitory but persistent rise of $h_{t}$ observed in the data with the same procedure used in Kydland and Zarazaga (2016). Curious readers can find in this reference the somewhat lengthy details, omitted here not to detract from the flow of the arguments.

As it should be apparent from the preceding section, the model economy involves a fairly large number of parameters and the attempt of estimating all of them with available statistical tools at an acceptable level of precision is doomed to failure given the limited available data, at most 36 annual observations, from 1977 to 2013, for the aggregate variables of interest. Therefore, it seemed wise to calibrate as many parameter values as possible with the widely accepted quantitative discipline imposed by the requirement that the steady state economic relationships between variables and/or parameters predicted by the model economy should match those prevailing in the actual economy, on average, over fairly long periods of time.

The parameters of the model economy whose values were set with a calibration approach are listed in Table 2. Whenever the calibrated values involved the use of historical averages, they correspond to the period 1997-2007. The observations pertaining to the Great Recession and its aftermath were deliberately excluded, on the grounds that the large changes that many macroeconomic variables experienced during that unusually deep contraction were persistent, but not permanent, and didn't have an everlasting impact, therefore, in the long run trends of the actual economy. The paper will take into account, however, that the increase of the capital income tax rate enacted in 2010 did change in 2013 , when it was slated to become effective, the steady state of the economy relative to that implied by the parameter values in Table 2 .

Missing from that table are the model parameters that can only be inferred from the high frequency movements of the economic variables under their influence, by definition absent from steady state relationships. Three types of parameters fall in this class: 1) the coefficients of stationary stochastic processes that drop out from the model equations in steady state, 2) parameters controlling intertemporal substitution effects in consumption and labor, the IES and the Frisch elasticity, and 3) parameters whose steady state values depend on those of these two macroelasticities.

Parameter in the first type of those just listed will be estimated with the techniques discussed in the next section. A different approach is followed, how- 
ever, for the second type of parameters, the IES and the Frisch elasticity. To avoid the controversies surrounding their empirically relevant values, the paper explored the extent to which the spending cuts prescribed by the budget sequestration were credible for different combination of values of these parameters, representative of those advocated by some and disputed by others in the literature.

Thus, for the labor-held constant intertemporal elasticity of substitution in consumption, captured by the parameter $1 / \sigma$ in the model, the paper will consider the following two values most commonly invoked as empirically relevant in the literature:

1. 0.5 ,

2. 1 .

As to the Frisch elasticity, captured by the parameter $\varphi$, the paper will consider the following five values:

1. 0.5 ,

2. 1 ,

3. 1.9 ,

4. 2.5 ,

5. 3 .

The first Frisch elasticity value is the median estimate inferred from socalled microeconomic studies, because they estimate that macroelasticity from evidence at the level of individuals or households, rather than from aggregate variables. The value of 1.9 has been proposed in an often-cited paper by Hall (2009). The value of 3 has been inferred by Prescott (2004) from a macroeconomic study, in the sense that he drew that as an implication from the behavior of the aggregate labor supply in countries with different labor income tax rates. Finally, for completeness, the values of 1 and 2.5 that fall in between the three previously discussed were considered as well.

In sum, given the disagreement on macroelasticity values, particularly for those of the Frisch elasticity, the paper will investigate the credibility of the budget sequestration cuts for five values of that elasticity and two of the IES, for a total of ten combinations of macroelasticity values.

Finally, recall that the third type of parameters that could not be calibrated includes those that are implied by steady state relationships that depend, precisely, on the values of the macroelasticities just discussed. That is the case of the parameters $\kappa$ and $\beta$ in the utility function.

For example, the Euler equation associated with the intertemporal first order necessary condition for the household's maximization problem described in section 3.1 implies the following steady state relationship between the latter parameter and the IES:

$$
1+\left(1-\tau_{k}\right)(r-\delta)=\frac{(1+\gamma)^{\sigma}}{\beta} .
$$


Accordingly, the value of $\beta$ was recalculated for each value of $\sigma$, taking into account that the studies by Poterba (1998), Siegel (2002), and Mehra and Prescott (2008) have established with some confidence that the long-run annual real return on capital for the U.S. economy, captured by the factor $(r-\delta)$ in the equation above, is in the order of magnitude of $8 \%$.

A similar procedures was applied to the parameter $\kappa$, whose dependence on the Frisch elasticity $\varphi$ is manifested by the intratemporal first order condition of the stand-in household's maximization problem.

Table 2

\begin{tabular}{|l|c|}
\hline \multicolumn{1}{|c|}{ Parameter/Variable } & Steady-State value \\
\hline$\eta$ (working-age annual population net growth rate) & 0.0126 \\
\hline$\gamma$ (TFP annual net growth rate) & 0.0078 \\
\hline$\delta$ (depreciation rate) & 0.0621 \\
\hline$i$ (before-tax annual net rate of return on private capital) & 0.0858 \\
\hline$x / y^{p r}$ (investment-output ratio) & 0.2121 \\
\hline$k / y^{p r}$ (private capital- private sector output ratio) & 2.5681 \\
\hline$\theta$ (private capital income share) & 0.38 \\
\hline$g y$ (fraction of private sector output absorbed by general government) & 0.0825 \\
\hline$v y$ (government enterprises value added-private sector output ratio) & 0.0156 \\
\hline$\sigma_{v y}$ (standard deviation of $v y$ ) & 0.0856 \\
\hline$n i y$ (net exports-private sector output ratio) & 0.026 \\
\hline$h^{p r}$ (fraction of time worked in private sector) & 0.21 \\
\hline$h^{p u}$ (fraction of time worked in public sector) & 0.03 \\
\hline$\sigma_{h p u}$ (standard deviation of $\left.h^{p u}\right)$ & 0.009 \\
\hline$\tau_{t}^{k}$ (capital income tax rate) & 0.35 \\
\hline$\tau_{t}^{h}$ (labor income tax rate) & 0.23 \\
\hline
\end{tabular}

\section{INFERRING THE CREDIBILITY OF THE BUDGET SEQUES- TRATION WITH A BUSINESS CYCLE ACCOUNTING AP- PROACH}

\subsection{OVERVIEW}

As indicated in the introduction, inferences about the credibility of the budget sequestration cuts as of the time it was launched will inspire more confidence if obtained with an economic model with well-known properties, such as the neoclassical growth model, modified to accommodate a variety of frictions and distortions perceived as important for correctly interpreting the information contained in the dynamics of macroeconomic variables of interest and that, at the same time, replicate the data exactly. These considerations led almost naturally to the analytical framework provided by the business cycle accounting approach, adapted for the purposes of this paper as indicated below. 
The first step in the particular implementation of the BCA carried out in this paper is the same as in CKM: represent the model in a state space form, suitable for estimating with maximum likelihood techniques those parameters of the stochastic processes governing the transitional dynamics of state variables that remain to be determined. The subsequent steps, however, are different from those followed by CKM, as they were tailored to answer the different question addressed by this paper.

In particular, given that the paper will make inferences about the credibility of the budget sequestration by looking at the dynamics it induced on macroeconomic variables, it was necessary to take into account that in 2013 they were under the influence not only of the spending cuts the budget sequestration started to trigger then, but also of the $3.8 \%$ surcharge on capital income tax discussed at the end of section 2.1. The confluence of tax and government spending regime changes raised the concern that the resulting dynamics could be too rich for available econometric tools to interpret correctly the relatively few observations at annual frequency contained in the period 1977-2013. An additional complication mentioned in the introduction is that that dynamics was also influenced by the IES and the Frisch elasticity, whose values are the subject of debate in the profession.

The lack of consensus on the values of the two macroelasticities just mentioned was addressed by implementing the adapted BCA procedure described below for each of the ten combinations of them listed in section 3.4. The concern about the eventual lack of precision of maximum likelihood techniques in the presence of complex transitional dynamics was resolved by estimating the unknown parameters with data free of that potential problem, that is, with the data from 1977, the first year for which they were available at the level of detail necessary for the application of the Gomme-Rupert methodology, until 2010, under the assumption that investment decisions for that year had been already made by the time the legislation increasing the capital income tax rate was passed.

The second step in the adaptation of the BCA approach to the purposes of this paper takes the parameter and states estimated in the first step, along with equilibrium decision rules from 2011 and 2012 that take into account the forthcoming higher capital income tax regime, to compute the evolution of the state variables up to 2012 .

The last step, different from that in CKM, is the critical one for the purposes of this paper. Recall that those authors exploit the state-space representation of the model to recover the wedges that replicate the data exactly at each point in time and then feed them one by one in the model economy to establish the marginal effects of each of them on the fluctuations of macroeconomic variables of interest. In this paper, whose goal instead is to assess the credibility of the budget sequestration cuts, what is fed into the model is different sequences of spending cuts over time, mimicking those which can be reasonably conjectured households and businesses had in mind at the moment the spending cuts started to be implemented in 2013. In principle, different set of wedges will be needed to replicate the data in each of the spending cuts scenarios. This makes it possible 
to compute the likelihood of the data for each of those sets of wedges and rank the underlying scenarios by the value of that likelihood. The scenario with the highest likelihood could be interpreted as the one most likely to have been driving the decisions economic agents were making at the time, as manifested in the relevant data.

\subsection{TECHNICAL DETAILS}

\subsubsection{STATE-SPACE REPRESENTATION}

The first step in implementing the adapted BCA approach just outlined is to represent the model in a state-space form, which is accomplished as usual, but specifying transition equations that govern the evolution of state variables over time and measurement equations that define the mapping between the states and the relevant observed data.

In general stochastic equilibrium models as the one in this paper, the link between observables and state variables in the measurement equations is provided by the equilibrium decisions rules which, as already anticipated, this paper computes with the standard practice of approximating the true decision rules with a first order Taylor expansion around the steady state. This ensures a linear mapping between state variables and observables. With the further assumption that the transition from one state to the other is governed by a linear Markov process, the state-state representation of the model economy of this paper can be formalized by the transition equation

$$
S_{t}=T S_{t-1}+Q \omega_{t}
$$

and the measurement equation

$$
Y_{t}=D S_{t-1}+C \omega_{t}
$$

In the transition equation (14), $S_{t}$ is a $6 \mathrm{x} 1$ vector of state variables at the end of period $t, T$ a $6 \times 6$ matrix, $\omega_{t}$ a $7 \times 1$ vector whose elements are all the exogenous shocks assumed present in the model economy, and $Q$ a $6 \times 7$ matrix whose elements are discussed in detail below.

In the measurement equation (15), $Y_{t}$ is the vector of observable variables, $D$ a $7 \times 6$ matrix, and $C$ a $7 \times 7$ matrix.

To see more clearly how the different elements of the model economy presented in the previous sections fit into the state-space representation, it will prove useful to spell out more fully the vectors and matrices involved as follows, starting with those of the transition equation.

$$
S_{t}=\left[k_{t+1}-k_{s s}, \ln \frac{e g a_{t}}{y_{t}^{p r}}-\ln g y, z_{t}-z_{s s}, \frac{n i_{t}}{y_{t}^{p r}}-n i y, \tau_{t}^{h}-\tau_{s s}^{h}, \tau_{t}^{x}-\tau_{s s}^{x}\right]^{\prime},
$$

where a subindex " $s s$ " identifies the steady state value of the period $t$ variable 
to the left ${ }^{3}$.

$$
T=\left[\begin{array}{cccccc}
T_{11} & T_{12} & T_{13} & T_{14} & T_{15} & T_{16} \\
0 & \rho_{g a} & 0 & 0 & 0 & 0 \\
0 & 0 & \rho_{z} & 0 & 0 & 0 \\
0 & 0 & 0 & \rho_{n i} & 0 & 0 \\
0 & 0 & 0 & 0 & \rho_{h} & 0 \\
0 & 0 & 0 & 0 & 0 & \rho_{x}
\end{array}\right]
$$

where the first row of this matrix is simply the result of replacing in the law of motion for the private capital stock, (3), the equilibrium decision rule for investment, $x_{t}$, approximated as a linear function of the end-of-period $t-1$ state of the economy, that is, of the state variables in $S_{t-1}$, and of the innovations $\omega_{t}$ hitting the economy in period $t$. The second row of $T$ simply replicates the stochastic process in equation (11). The rest of the rows of this matrix represent the wedges, expressed in terms of ratios to private sector output when appropriate, as stochastic Markovian processes that depend only on their own past. Interactions between these processes were ruled out by assumption, for the same reasons given earlier: the limited data available would have prevented the reliable estimation of the large number of parameters implied by a less parsimonious specification. ${ }^{4}$

$$
\omega_{t}=\left[\varepsilon_{t}^{g y}, \varepsilon_{t}^{h p u}, \varepsilon_{t}^{g e}, \varepsilon_{t}^{z}, \varepsilon_{t}^{n i}, \varepsilon_{t}^{\tau h}, \varepsilon_{t}^{\tau x}\right]^{\prime},
$$

where the first three elements corresponds to the innovations identified in equations (11), (12), and (13), and the remaining elements capture the innovations to the four wedges $z_{t}, n i_{t}, \tau_{t}^{h}$, and $\tau_{t}^{x}$.

$$
Q=\left[\begin{array}{ccccccc}
Q_{11} & Q_{12} & Q_{13} & Q_{14} & Q_{15} & Q_{16} & Q_{17} \\
\sigma_{g y} & 0 & 0 & 0 & 0 & 0 & 0 \\
& 0_{4 x 3} & & & H_{4 x 4} & &
\end{array}\right],
$$

where the elements of the first row are coefficients implied by the linearized equilibrium decision rule for the capital stock and the elements of the $4 \times 4$ diagonal submatrix $H$ estimated parameters that characterize the stochastic processes for the wedges.

As inspection of the elements of the matrix $\mathrm{Q}$ reveals, the exogenous stochastic component of government absorption, $g a_{t}$, is assumed to be uncorrelated with all other innovations in the model. The innovations to the wedges, however, represented by the last four elements of the vector $\omega$, are allowed to be correlated.

Turning to the measurement equation, $Y_{t}$ is the vector of observable variables given by

\footnotetext{
${ }^{3}$ Notice that for consistency with the timing convention adopted in the law of motion of capital (3), the capital stock at the end of period $t$ is denoted in the vector $S_{t}$ as the beginning of period $t+1$ capital stock, $k_{t+1}$.

${ }^{4}$ It is not clear, in any case, that the interactions would be significant, as they are not statistically different from zero in CKM.
} 
$\left[y_{t}^{p r}-y_{s s}^{p r}, c_{t}-c_{s s}, x_{t}-x_{s s}, h_{t}^{p r}-h_{s s}^{p r}, \ln \frac{e g a_{t}}{y_{t}^{p r}}-\ln g y, \ln h_{t}^{p u}-\ln h^{p u}, \ln \frac{v a_{t}^{g e}}{y_{t}^{p r}}-\ln v y\right]^{\prime}$,

where again a subindex "ss" identifies the steady state value of the corresponding variable.

It is worth to clarify at this point a potential confusion created by the inclusion of the element $\ln \frac{e g g_{t}}{y_{t}^{p r}}-\ln g y$ in the vector of observables $Y_{t}$. Strictly speaking, the variable directly observable in the data is $g a_{t}$, not the individual components identified in equation (10). However, as this equation makes apparent, in the absence of the temporary policy regime, the systematic stochastic component $e g a_{t}$ is equal to $g a_{t}$ and therefore, observable as well. This equality holds, therefore, between 1997 and 2012, before the budget sequestration was triggered. When it breaks down in 2013, ega $a_{t}$ is no longer observable but it can be inferred from the data and the spending cuts for that year implied by the legislation that enacted the budget sequestration. In particular, in the absence of the spending cuts, the observation $g a_{2013}$ would have been higher by $s c_{2013}$, the amount by which the sequestration would reduce government spending that year, as per the CBO estimate reported in Table 1. Thus, ega $a_{2013}$ can be inferred from the equality e $g a_{2013}=g a_{2013}+s c_{2013}$ implied by equation by (10).

The $7 \times 6$ matrix $D$ can be rewritten as

$$
D=\left[\begin{array}{cccc} 
& D_{4 x 6} & \\
0 & \rho_{g a} & 0 & \\
0 & 0 & 0 & 0_{3 x 3} \\
0 & 0 & 0 &
\end{array}\right],
$$

where the elements $D_{i j}$ of the $4 \times 6$ submatrix $D$ consist of the coefficients of the linearized equilibrium decision rules for the endogenous variables in the vector $Y_{t}$ and the element $\rho^{g a}$ restates in matrix notation the first term of equation (11).

Finally, the $7 \mathrm{x} 7$ matrix $\mathrm{C}$ is given by

$$
C=\left[\begin{array}{cccc}
\multicolumn{5}{c}{C_{4 x 7}} \\
\sigma_{g y} & 0 & 0 & \\
0 & \sigma_{h p u} & 0 & 0_{3 x 4} \\
0 & 0 & \sigma_{v y} &
\end{array}\right],
$$

where the elements $C_{i j}$ of the $4 \times 7$ submatrix $C$ are determined by the equilibrium decision rules and the last three rows simply restate in matrix notation the second term in equations (11), (12), and (13).

With all the necessary elements in place, the next section briefly discusses how the state-state representation is applied to the estimation of the unknown parameters of the model.

\subsubsection{ESTIMATION OF UNKNOWN STATES AND PARAMETERS}

Inspection of the list of calibrated parameters in Table 2 reveals that it contains only the steady-state values of the stochastic component of the government absorption of goods and services specified by (11) and of the stochastic 
processes for the wedges. The other parameters for those processes appearing in the state-space representation of the model, represented by the elements in the last five rows of the matrix $T$ and in the last two of the matrix $Q$, remain to be determined. The reason for not calibrating these parameters is that the wedges are shortcuts for not explicitly modeled frictions and distortions that tend to fade over time and will be missed, therefore, by looking at data and statistics meant to reveal only the underlying long-run features of the economy.

In particular, if the Great Recession, as often argued, was indeed triggered by financial frictions, it seemed important to let the data for that episode to influence the choice of the parameter values that govern the fluctuations of wedges meant to pick up those and other relatively short-lived frictions possibly active during that episode and its aftermath. The same observation applies to the government spending variable $g a_{t}$, because even if strictly speaking is not treated as a wedge, the nature of its short-run fluctuations will have a potentially significant impact on the inferences that this paper will make on the credibility of the budget sequestration cuts. These considerations suggested that those inferences would gain in precision by estimating the parameters under discussion with all the available data, a task that can be accomplished with standard maximum likelihood procedures particularly easy to implement when the relevant variables are represented in state-space form.

To gain intuition on the nature of those tools, notice that the estimates of the unknown parameters in the matrices $T$ and $Q$ will be influenced by the difference between the data for the variables in the measurement equation and their predicted values implied by the corresponding decision rules, in turn a function of the parameters that need to be estimated. The Kalman filter, present in any well packaged econometrics toolkit, was especially developed to deal with this "circularity" problem.

Due to a computational difficulty, however, it was not possible to apply that filter to the data for the whole 1977-2013 period. The root of the problem is the increase of the capital income tax rate, starting in 2013, enacted by the 2010 legislation documented in section 2.1. The paper assumes that households and businesses became fully aware of the higher tax rate in 2011 and started to incorporate it in their decisions then. As made apparent in the previous section, the resulting equilibrium decision rules enter in the state-space representation of the model, but standard algorithms that implement the Kalman filter are not particularly well designed to deal with changes of those rules over the estimation period. To circumvent this difficulty, the filter was applied to the data for the period over which the equilibrium decision rules stayed the same according to the arguments above, that is, for the period 1977-2010. Following standard practice, the initial values of the state variables were set equal to their steady state values whenever necessary to start the algorithm.

It is important to reiterate at this point that since the paper doesn't take a stand on which of the variety of values for the IES and the Frisch elasticity proposed in the literature is empirically relevant, the parameters that are the subject of this section had to be estimated for each of the ten combination of values of those two macroelasticitites listed in section (3.4). 
The resulting ten different sets of estimates of parameters and state variables made it possible to proceed to the next step of the modified BCA methodology proposed in this paper. Before getting any deeper into the details of that adaptation, it is useful to point out that, once parameter values and state variables have been revealed by the appropriate estimation procedure, the wedges that replicate the data exactly can be easily recovered from equation (15), which implies:

$$
\omega_{t}=C^{-1} Y_{t}-C^{-1} D S_{t-1} .
$$

\subsubsection{INCORPORATING THE TAX REGIME CHANGE}

In order to interpret the dynamics of macroeconomic variables under the effects of the sequester correctly, it is necessary to establish first how that dynamics was altered by the increase of the capital income tax rate repeatedly mentioned before. With all the parameter values fixed by the last step, this could be accomplished with an algorithm capable of simulating the path of the variables of the model during 2011 and 2012, that is, for the years in which the capital income tax change repeatedly mentioned was anticipated, but not effective yet. Juillard (2006) suggested the general principle behind such an algorithm in the context of perturbation methods: treat perfectly anticipated current and future deviations of a policy variable from its steady state value as exogenous deterministic state variables and approximate the decision rules around the steady state with standard perturbation methods.

In the case of the increase of the capital income tax rate under consideration, the algorithm involves adding a deterministic state variable and modifying the state-space representation of the model accordingly, as follows:

$$
\begin{aligned}
S_{t} & \left.=\mathfrak{T} S_{t-1}+Q \omega_{t}+M\left(\tau_{t+1}^{k}-\tau_{\text {new }}^{k}\right)\right], \\
Y_{t} & \left.=\mathfrak{D} S_{t-1}+\mathfrak{C} \omega_{t}+P\left(\tau_{t+1}^{k}-\tau_{\text {new }}^{k}\right)\right],
\end{aligned}
$$

where $t=2011,2012, M$ and $P$ are matrices of coefficients with dimensions $6 \times 1$ and $7 \times 1$, respectively, and $\tau_{\text {new }}^{k}$ represents the tax rate on capital income effective since 2013, 0.388, obtained by adding to the capital income tax rate calibrated to the period 1977-2007, 0.35, the surcharge enacted in 2010, 0.038. The matrices $\mathfrak{T}, \mathfrak{D}$, and $\mathfrak{C}$ simply reflect the fact that the elements of those matrices corresponding to decision rules coefficients are different from the corresponding elements in the matrices $T, D$, and $C$ in the previous step, because they have been computed by linearizing the model equations around the new steady state implied by the permanently higher tax rate. The fact that the matrix $Q$ is the same makes apparent, though, that the parameters of all the exogenous stochastic processes have been kept at the values estimated in the previous step.

Notice that the reformulation of the state-space representation expands the state space with the additional variable $\left[\tau_{t+1}^{k}-\left(\tau^{k}+0.038\right)\right]$, taking into account that investment decisions in period $t$ depend on the after-tax rate of return on period $t+1$, as the explicit derivation of the Euler equation would make

apparent. Thus, when $t=2011, \tau_{t+1}^{k}$ is still at the level of the old capital income 
tax rate $\tau^{k}, 0.35$, effectively adding a perfectly known in advance, deterministic state variable that, along with the other ones present in the original formulation, determine the linearized equilibrium decision rules. However, in $t=2012$ those rules cease to be a function of this extra state variable, which drops out of the model because $\tau_{t+1}^{k}=\tau_{2013}^{k}=\tau^{k}+0.038=\tau_{n e w}^{k}$.

In any case, what is important to keep in mind is that the goal of this step is to determine the effect of the preannounced tax regime change on the state variables at the end of period 2012, whose level will be an important determinant of the dynamic of macroeconomic variables at the time that dynamics started to register as well the influence of the budget sequestration triggered in 2013. The next step illustrates precisely the implication of that measure for the equilibrium decision rules and for the evidence that will be exploited to make inferences about the extent to which the reduced spending authority it implied was regarded as an effective fiscal stabilization tool.

\subsubsection{INCORPORATING THE BUDGET SEQUESTRATION CUTS}

Applying to anticipated spending cuts the same principle behind the algorithm of the preceding section results in the following state-space representation of the model:

$$
S_{t}=\mathfrak{T} S_{t-1}+Q \omega_{t}+\mathfrak{M} \Delta_{t}
$$

and

$$
Y_{t}=\mathfrak{D} S_{t-1}+\mathfrak{C} \omega_{t}+\mathfrak{P} \Delta_{t},
$$

where $\Delta_{t}$ is a nx1 column vector whose elements will capture different spending cuts scenarios discussed in the next section and $\mathfrak{M}$ and $\mathfrak{P}$ are conformable matrices, with dimensions $6 \mathrm{xn}$ and $7 \mathrm{xn}$ respectively.

Notice that the matrices $\mathfrak{T}, \mathfrak{D}$, and $\mathfrak{C}$ are the same as those that capture the change in decision rules induced by the capital income tax rate increase because, as argued in section 2.1, the budget sequestration spending cuts were temporary in nature and assumed accordingly not to have any impact on the steady state equilibrium of the economy. Operationally, this means that the steady state value of the spending cuts is 0 and, therefore, that the deviations of the sequence of current and future spending cuts from their steady state value are the spending cuts themselves.

It is worth to recall also here that, as discussed when introducing the elements of the state-space representation of the model in section 4.2.1, the variable $\ln e g a_{2013}$ in the vector $Y_{t}$ is not directly observable in 2013, but can be inferred by adding to the government absorption of goods and services observed that year, $g a_{2013}$, the spending cuts that the budget sequestration prescribed for that year, according to the CBO estimates documented in Table 1.

The basic idea guiding the methodological steps described in this section is that the question asked by this paper, the extent to which U.S. households and businesses believed that the budget sequestration would be implemented in the terms originally announced, can be answered by examining the dynamics 
of the endogenous macroeconomic variables in the vector $Y_{t}$ under different sequences of current and future spending cuts including, of course, the ones that the budget sequestration was projected to trigger. If the budget sequestration scenario is, among all those considered, the one that accounts best for the data according to some widely accepted metric, then it is fair to conclude that the future spending cuts it implied were fully credible. The paper implements this idea empirically by considering two alternative scenarios that capture different degrees of skepticism that economic agents may have had about the sustainability of budget sequestration cuts that, if implemented as implied by the 2013 legislation that ended up triggering them, would bring the discretionary component of government spending, captured in the model economy by the ratio $\frac{g a_{t}}{y^{p r}}$, to an unprecedented historically low level.

Concretely, the elements in the vector $\Delta_{t}$ will correspond to the sequence of spending cuts implied by the following three scenarios:

1. Spending cuts implied by budget sequestration projected by the CBO, as documented in Table 1:

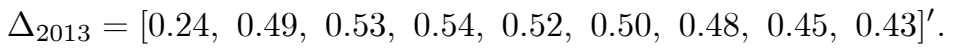

2. Spending cuts half the size of those implied by budget sequestration:

$$
\Delta_{2013}=\frac{1}{2}[0.24,0.49,0.53,0.54,0.52,0.50,0.48,0.45,0.43]^{\prime} .
$$

3. Budget sequestration spending cuts suspended after 2013:

$$
\Delta_{2013}=[0.24] \text {. }
$$

\subsubsection{ASSESSING THE CREDIBILITY OF THE BUDGET SEQUESTRA- TION}

The final steps in making inferences about the credibility of the budget sequestration with the adapted version of the BCA methodology discussed so far are as follows:

1. Back out the 2013 realized exogenous shocks for each spending cut scenarios and combination of macroelasticities from (19):

$$
\omega_{i, 2013}=\mathfrak{C}_{i}^{-1} Y_{i, 2013}-\mathfrak{C}_{i}^{-1} \mathfrak{D}_{i} S_{i, 2012}-\mathfrak{C}_{i}^{-1} \mathfrak{P}_{i} \Delta_{j, 2013},
$$

where the subindex $i$ indicates the the elements of the matrix or vector bearing it correspond to those associated with the particular combination $i$ of values of the IES and the Frisch elasticity, out of the ten considered, and the subindex $j$ identifies the particular spending cuts scenario $j$, out the three considered.

2. Define

$$
\widetilde{\omega}_{i, 2013}=\left[\widetilde{\varepsilon}_{2013}^{g y}, \widetilde{\varepsilon}_{i, 2013}^{z}, \widetilde{\varepsilon}_{i, 2013}^{n i}, \widetilde{\varepsilon}_{i, 2013}^{\tau h}, \widetilde{\varepsilon}_{i, 2013}^{\tau x}\right]^{\prime},
$$

where $\widetilde{\omega}_{i, 2013}$ is the vector obtained by excluding from $\omega_{i, 2013}$ those exogenous shocks whose inferred values in the previous step are not influenced 
by the spending cuts or the values of the macroelasticities. These exclusion conditions are met by the realized innovations $\widetilde{\varepsilon}_{t}^{h p u}$ and $\widetilde{\varepsilon}_{t}^{g e}$, as it can be easily checked with equations (12) and (13).

3. Calculate the likelihood of the data for each scenario and combination of macroelasticities from:

$$
\begin{aligned}
& f\left(Y_{2013} \mid \Delta_{j, 2013}, S_{i, 2012}, \widetilde{\omega}_{i, 2013} ;(\sigma, \varphi)_{i}\right)= \\
& (2 \pi)^{-\frac{5}{2}} \cdot\left[\operatorname{det} \widetilde{\Sigma}_{i}\right]^{-\frac{1}{2}} \cdot \exp \left(-\frac{1}{2} \widetilde{\omega}_{i, 2013}^{\prime} \widetilde{\Sigma}_{i}^{-1} \widetilde{\omega}_{i, 2013}\right),
\end{aligned}
$$

where the subindices $i$ and $j$ have the same interpretation as above and the pair $(\sigma, \varphi)_{i}$ identifies therefore the particular combination $i$ of values for the IES and the Frisch elasticity, out of the ten considered. Accordingly, $\widetilde{\Sigma}_{i}$ is the variance-covariance matrix of the shocks included in $\widetilde{\omega}_{i, 2013}$ for each pair of macroelasticities values $(\sigma, \varphi)_{i}$ obtained in the estimation stage. Furthermore, the state variables carried over from the past are presumed to capture the true state of the economy in 2012.

4. Use the information provided by the likelihood of the data under different combinations of macroelasticity values and spending cuts spending cuts scenarios to make inferences about the extent to which the fiscal austerity implied by the budget sequestration was credible as a fiscal stabilization tool.

\section{RESULTS}

Table 3 reports the logarithm of the likelihood obtained in the previous step for each of the three spending cuts scenarios and each of the ten combinations of IES and Frisch elasticities considered.

As it can be verified by comparing the last column of Table 3 with the preceding two, the scenario in which agents believed that the spending cuts implied by the budget sequestration would be implemented in full is the least likely to account for the data for all macroelasticity values. In fact, regardless also of the assumed macroelasticity values, the likelihood of the data is higher for the scenario in which economic agents in the model economy made their 2013 decisions expecting that the budget sequestration would last only for one period. But according to the Table 3, the highest likelihood of the data is associated with the intermediate scenario, in which the anticipated spending cuts are only half of those prescribed by the budget sequestration.

\section{CONCLUSION}

The fiscal imbalances that many developed countries were confronting before the Great Recession became more severe with the additional burden implied by the unprecedented levels that their governments' debt reached during that unusually deep contraction and its aftermath. 
Table 3

Log likelihood of innovations that replicate 2013 data exactly

\begin{tabular}{|c|c|c|c|}
\hline \multicolumn{3}{|c|}{$\sigma=1$} \\
\hline Frisch Elasticity & 2013 Only & $\begin{array}{c}\text { Half-Size 2013 - 2021 } \\
\text { Prescribed Cuts }\end{array}$ & $\begin{array}{c}\text { Full-Size 2013 - 2021 } \\
\text { Prescribed Cuts }\end{array}$ \\
\hline 0.5 & -6.3645 & -6.2516 & -6.5787 \\
\hline 1.0 & -6.4123 & -6.3064 & -6.6604 \\
\hline 1.9 & -6.4561 & -6.3598 & -6.7472 \\
\hline 2.5 & -6.4729 & -6.3814 & -6.7838 \\
\hline 3.0 & -6.4846 & -6.3959 & -6.8088 \\
\hline Note: Model with intertemporal wedge $\tau_{x} ;$ Likelihood calculation excludes $e_{h p u}$ and $e_{v y}$. & \\
\hline
\end{tabular}

\begin{tabular}{|c|c|c|c|}
\hline \multicolumn{3}{|c|}{$\sigma=2$} \\
\hline Frisch Elasticity & 2013 Only & $\begin{array}{c}\text { Half-Size 2013-2021 } \\
\text { Prescribed Cuts }\end{array}$ & $\begin{array}{c}\text { Full-Size 2013 - 2021 } \\
\text { Prescribed Cuts }\end{array}$ \\
\hline 0.5 & -6.4958 & -6.2636 & -6.5538 \\
\hline 1.0 & -6.5935 & -6.3610 & -6.6774 \\
\hline 1.9 & -6.6871 & -6.4594 & -6.8148 \\
\hline 2.5 & -6.7221 & -6.4981 & -6.8732 \\
\hline 3.0 & -6.7435 & -6.5223 & -6.9111 \\
\hline
\end{tabular}


In the case of the U.S., the situation looked grave enough to compel a majority of lawmakers to enact legislation intended to finally address that country's own long-standing fiscal imbalances. This was indeed the declared goal of a contingent clause included in the Budget Control Act of 2011, which mandated a budget sequestration-in practice a reduction of discretionary government spending-over the period 2013-2021 for a cumulative amount of $\$ 1.2$ trillion-about $8 \%$ of nominal GDP at the time if the U.S. Congress failed to reach agreement on achieving that same amount of fiscal deficit reductions with other measures.

The fiscal stabilization measure of last resort nature of the budget sequestration was apparent in the fact that, if implemented as implied by the legislation, according to CBO projections, it would bring government discretionary spending to the lowest level on record as a share of GDP, eventually impairing the ability of the public sector to adequately perform core functions under its management and oversight. Given these blunt implications, it seems legitimate to wonder if households and firms believed that the budget sequestration could be sustained over time. For example, they couldn't be but skeptical if they correctly perceived that the measure lacked popular support and that the U.S. had reached, therefore, its "fiscal limit"-to borrow terminology from Leeper (2013)in addressing its fiscal imbalances with perhaps unpopular spending cuts. It follows that sizing up the beliefs that economic agents may have had about the ultimate fate of the severe form of spending austerity implied by the budget sequestration could provide useful insights on how fiscal stabilization will be ultimately achieved in the U.S.

The paper is motivated by the proposition that the economic decisions optimizing households and firms made when the budget sequestration was launched were necessarily informed by their conjectures about how the rather draconian across-the-board spending cuts prescribed by that fiscal stabilization measure of last resort would actually proceed over time. The paper exploits this connection between expectations and outcomes to make inferences about the extent to which economic agents believed that government expenditures would be indeed reduced by as much as and for as along as implied by the budget sequestration.

In order for those inferences to inspire enough confidence, the paper considered important to draw them with an economic model flexible enough to accommodate different views about what constitutes an acceptable abstract representation of the actual economy under study. An adapted version of the BCA approach, originally developed by Chari, Kehoe, and McGrattan (2007) for other purposes, was deemed appropriate for the task.

One of the advantages of the BCA methodology is that it introduces in an otherwise frictionless economy so-called "wedges" that account for a variety of distortions not explicitly modeled. In the context of a state-space representation of the model economy, it is possible to recover the innovations to those wedges and other variables that replicate the data exactly. The basic idea behind the particular implementation of the BCA methodology adopted for this paper is that different conjectures about the evolution of spending cuts associated with the budget sequestration will induce different configurations in the wedges and, 
therefore, that their underlying distributions can be used to calculate the likelihood of the data under different assumptions about what those conjectures might have been.

The paper implements that methodological blueprint by feeding into the model economy three different sequences of spending cuts that it seemed reasonable to argue households and businesses may have had in mind at the moment the budget sequestration started to be executed in 2013. The three sequences correspond to two extreme scenarios and one intermediate one. One of the extreme scenarios assumes that the budget sequestration was fully credible, in the sense that the sequence of spending cuts effectively executed coincides with that projected by the CBO, as documented in Table 1 . The other extreme scenario postulates that economic agents were highly skeptical when the budget sequestration was launched that it would be enforced beyond 2013. The intermediate scenario assumes that the budget sequestration was only half credible, that is, that in the end the spending cuts would be only half the size of those in the full credibility scenario.

The main finding of the paper is that, for all the ten combinations of macroelasticity values considered, the data favors the intermediate spending cut scenario over the two extreme ones. The paper is silent as to why economic agents seemed to doubt that the budget sequestration would be executed in the terms enacted in existing legislation. But it is difficult to rule out the possibility that those doubts were grounded on the correct assessment that as a fiscal stabilization measure of last resort, the budget sequestration was too draconian to enjoy enough popular support to be implemented in full.

That assessment is reinforced by recent studies that attribute to alternative fiscal stabilization channels the puzzling dynamics that key macroeconomic variables exhibited during the Great Recession and the rebound that followed it. For example, Kydland and Zarazaga (2016) showed that the prospects of higher capital income tax rates can go a long way in accounting for the weakness of the recovery from that unusually severe downturn. Fratto and Uhlig (2014) note that the "missing deflation" during that episode predicted by some models could be explained away by incorporating in the analysis the built-in mechanism emphasized by the fiscal theory of the price level, which postulates that under certain conditions fiscal stabilization can be accomplished by unanticipated increases in the price level that reduce the value of the government debt in real terms. It seems fair to conclude that future research revisiting these additional, not mutually exclusive channels of fiscal stabilization with the methodology proposed in this paper holds the promise of shedding further light on how the U.S. is most likely to achieve the coveted fiscal stabilization that, according to the finding documented above, economic agents didn't expect could be delivered by reductions of government discretionary spending alone. 


\section{REFERENCES}

Congressional Budget Office (2012): "An Update to the Budget and Economic Outlook: Fiscal Years 2012-2022," August.

Congressional Budget Office (2013): "The Budget and Economic Outlook: Fiscal Years 2013-2023." February.

Chari, V.V., P. J. Kehoe and E. R. McGrattan (2007): "Business Cycle Accounting," Econometrica 75 (3): pp. 781-836.

Fratto, C, and C. Uhlig (2014): "Accounting for Post-Crisis Inflation and Employment: A Retro Analysis," National Bureau of Economic Research, Working Paper 20207.

Gomme, P. and P. Rupert (2007): "Theory, measurement and calibration of macroeconomic models," Journal of Monetary Economics 54: 460-497.

Greenwood, J., Z. Hercowitz, and P. Krusell (1997): "Long-Run Implications of Investment-Specific Technological Change," American Economic Review 87(3): pp. 342-362.

Hall, R. E. (2009): "Reconciling Cyclical Movements in the Marginal Value of Time and the Marginal Product of Labor," Journal of Political Economy 117 (2): 281-323.

Juillard, M. (2006): "Policy Change and DSGE models," manuscript.

Kaldor, N. (1961): "Capital Accumulation and Economic Growth," in The Theory of Capital, ed. F. A. Lutz and D. C. Hague, 177-222. New York: St. Martins Press.

King, R.G, C. I. Plosser, and S. T. Rebelo (1988a): "Production, Growth and Business cycles: I. The Basic Neoclassical Model," Journal of Monetary Economics 21: 195-232.

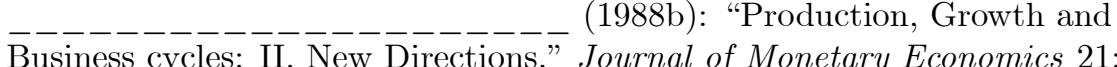
309- 341.

Kydland, F. E. and C. E. J. M. Zarazaga (2016): "Fiscal Sentiment and the Weak Recovery from the Great Recession: A Quantitative Exploration," Journal of Monetary Economics 79: pp. 109-125.

Leeper, E. M. (2013):"Fiscal Limits and Monetary Policy," Central Bank Review 13: pp. 33-58.

Lucas, R. E., Jr. (2011): "The Weekend Interview with Robert Lucas: Chicago Economics on Trial," The Wall Street Journal, September 24, p. A13.

Mehra, R. and E.C. Prescott (2008): "The Equity Premium: ABCs," in Handbook of the Equity Risk Premium, edited by R. Mehra. North Holland. Amsterdam. 
Poterba, J.M. (1998): "Rate of return to corporate capital and factor shares: new estimates using revised national income accounts and capital stock data." Carnegie-Rochester Conference Series on Public Policy 48: 211-246.

Prescott, E. C. (2004): "'Why Do Americans Work So Much More Than Europeans?"

Federal Reserve Bank of Minneapolis Quarterly Review 28: pp. 2-13.

Siegel, J. (2002): Stocks for the Long Run, 3rd ed., Irwin, New York.

Trabandt, M. and H. Uhlig (2011): "The Laffer curve revisited," Journal of Monetary Economics 58(4): 305-327. 